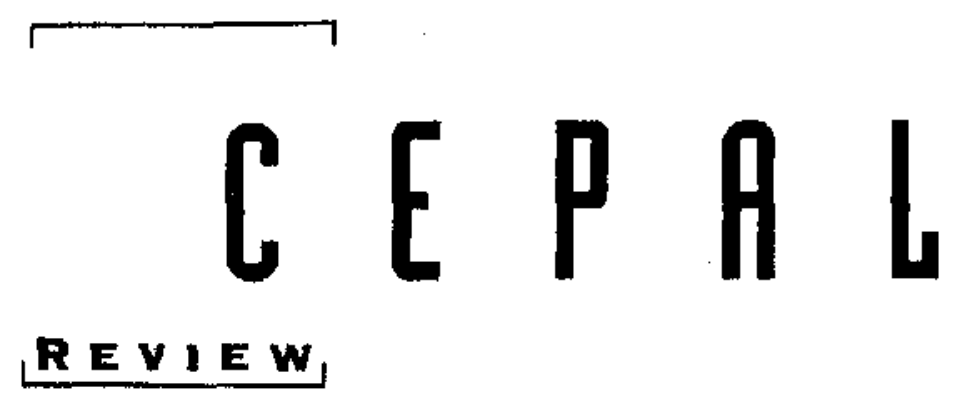

\author{
NUMEEF 65 \\ AUQUST 1998 \\ SANTIAGO, CHILE \\ O S CA ALTIMIA \\ Director of the Review \\ EUGENIO LAHEAA \\ Technical Secretary
}

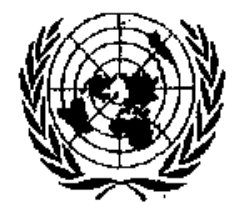


Income distribution, poverty and social expenditure In Latin Amerlca

José Antonio Ocampo

Military expenditure and development in Latin America

Eugenio Lahera and Marcelo Ortuzar

Growth, dlstrlbutive justice and social policy

Andrés Solimano

Equity, forelgn investment and International competitiveness

Adolfo Figueroo

Tensions in Latin American structural adjustment:

allocatlon versus distribution

Daniel M. Schydlowsky

Compethliveness and labour regulations

Luis Beccaria and Pedro Galín

Latin American femilles: convergences and divergences in models and pollcles

Irma Arriagada

Free trade agreements and female labour: the Chilean sltuation

Alicia Frohmann and Pilar Romaguera

Macroeconomic trends in Paraguay from 1989 to 1997:

consumptlon bubble and financial crisis

Stephane Straub

The strategies pursued by Mexican firms in their efforts

to become global players

Alejandra Salas-Porras

Pegulating the private provision of drinking water and sanitation services

Terence R. Lee and Andrei S. Jouraviev

Quallty management promotion to Improve competitiveness

Hessel Schuurman

Recent ECLAC publlcations 


\section{Regulating the private provision of drinking water and sanitation services}

Terence R. Lee

Andrei S. Jouraviev

Environment and Development Division, ECLAC.
Ever since the 1970s, the governments of the region have been transferring public companies and other State institutions to the private sector in one manner or another. Privatization has now spread to all sectors of the economy, including drinking water supply and sanitation services. Private sector involvement in the provision of these services offers potentially significant efficiency gains, but it will not, in itself, guarantee lasting welfare improvement unless these services are provided in a competitive market. If not, the results will depend on the regulatory regime within which the industries operate, and the effectiveness of this regime will be determined by the ability of governments to seek and create institutional and regulatory conditions that oblige suppliers to be efficient and responsive to the needs of their customers. This article focuses on the issues to be confronted in preparing a suitable regulatory framework for the drinking water supply and sanitation sector. 


\section{I}

\section{Introduction}

The provision of drinking water and sanitation services has been marked in Latin America and the Caribbean by enormous deficiencies or faulty management on the part of the government. This is the main reason for the present widespread adoption of measures to increase private sector participation. Such participation could be expected to bring potentially large efficiency gains, but it will not in itself be sufficient to guarantee lasting welfare improvement, because drinking water and sanitation services tend to be natural monopolies when their provision by a single firm results in lower costs than if they were provided by two or more firms. In this case, competition is either not possible or would entail inefficient and prohibitively costly duplication of fixed assets, as well as failing to take advantage of economies of scale.

Unless there is a competitive market, results will depend on the ability of governments to find adequate institutional and regulatory solutions which oblige suppliers to be efficient and responsive to their customers' needs. It is therefore important to identify the features which contribute to the success or failure of such efforts. This is particularly important because the regulation of private monopolies is no easy matter: "effective regulation is necessarily a complex business, and to pretend otherwise is likely to have damaging long-term consequences for the industries concerned. Undue simplification of the initial framework of regulation for privatized monopolies will .... very frequently lead to the emergence of much more serious difficulties in the longer term" (Vickers and Yarrow, 1988). Furthermore, governments in the region have little experience in this field, since most companies in this sector used to be State-owned and regulatory systems for them were never developed.

A sudden shift from public ownership and bureaucratic control to a regulated private monopoly completely changes the demands made on the management institutions of the sector and also requires a thorough reconsideration of the management policies adopted for drinking water and sanitation services in the past. Privatization demands not only that the State should withdraw from many activities, but also that it should take on some new ones which are often of a very different nature and require different skills and knowledge on the part of public sector personnel. With regard to drinking water and sanitation services, experience shows that privatization does not simply end with the transfer of the assets concerned but requires continuing regulatory action by the public sector.

\section{II}

\section{Regulatory system design}

Two broad modes of regulation may be distinguished: structure regulation, which determines which organizations or types of organizations can engage in which activities, and conduct regulation, which concerns the permitted behaviour of organizations in their chosen activities (Vickers, 1991). Thus, conduct regulation exercises direct control over the objectives of the regulated firm, while structure regulation exercises direct control over the structural environment of the firm, but not its behaviour (Perry,
1984). The regulation of natural monopolies will usually require a combination of the two.

The nature of conduct regulation is largely dictated by structure regulation. In order to minimize the scope for govemment failure, there should be as little conduct regulation as possible.

Regulators should seek to create a reward structure which confronts firms with strong incentives to adopt socially optimal choices rather than simply engaging in micro-management, which is not much 
different from the management of State-owned enterprises; there is little merit in converting a public monopoly into a heavily-regulated private monopoly. The creation of such a structure involves identifying the precise sources of market failures, using structure regulation to isolate the activities with which they are associated and focusing conduct regulation directly on the areas where market failures are most pronounced. If structure regulation fails to achieve this end, conduct regulation may be ineffective in restraining monopoly power and may induce productive and allocative inefficiencies. Thus, appropriate regulatory design maximizes the benefits from removing market failures, in relation to the cost of government intervention, because the marginal benefits of regulation decline linearly as intervention increases, while the costs rise exponentially (Jones, 1994).

To what extent should public authorities rely on structure or conduct regulation? This is an empirical problem which necessarily depends on industryspecific conditions, such as the scope for new entry and competition afforded by the underlying technological and market conditions and the degree of asymmetry of information.
There are sectors where market liberalization and restructuring can be counted on to supply the beneficial pressures of competition which will avoid monopolistic forms of conduct. In others, however, there are industries, including drinking water and sanitation services, where potential entry and competition ane limited by the current technology in transmission and distribution activities. In these industries, even if all barriers to entry were removed, new entrants would not materialize except at the expense of productive inefficiency related to the prohibitively costly duplication of fixed assets. In industries with a high degree of natural monopoly, conduct regulation, rather than structural reform and the promotion of competition, is the appropriate policy response.

Other important factors are the nature of the infrastructural components which define a firm as a natural monopoly and the speed of changes in the underlying technological and market conditions (Beesley and Littlechild, 1989). Systems of a local nature, where the rate of change is slow, such as drinking water and sanitation services, offer the most promising conditions for conduct regulation. If the system is of a national scale and the rate of change is rapid, however, such regulation will be mone difficult.

\section{III}

\section{Asymmetric Informatlon}

Adequate information is of paramount importance for effective regulation, but regulators are fundamentally constrained by the lack of information on the utilities they' regulate: "the problem of regulation is essentially a problem of control with incomplete information" (Laffont, 1994). The regulated company's management always has better information than the regulatory agency about both industry costs and demand conditions, including the effects of the incorporation of new technologies and the most efficient means of operation, and also about the firm's own behaviour, particularly the level of its efforts to reduce costs. Asymmetric information allows a firm to extract rents from its monopoly of information and obtain supernormal profits, resulting in overall welfare loss or allocative inefficiency.
Asymmetric information has three major implications:

i) the prospects of generating information for regulatory purposes should be an important consideration in a government's decision about the nature of the regulatory regime and the structure of the industry (Beesley and Littlechild, 1989).

ii) instead of using command-and-control methods: i.e., instructing the firm on every aspect of its operation and requiring it to follow the orders it is given and relying on micro-management, the regulatory goal should be to design incentive mechanisms for the regulated firm that will motivate it to use its superior information to maximize society's objectives while pursuing its own selfinterest, rather than merely extracting rents from its 
monopoly of information (Acton and Vogelsang. 1989; Sappington, 1994).

iii) regulators should have a legal right to have access to the inside information of the regulated firm, as for example through audits, and they should also ensure the transparency of information. Transparency of accounts is a very important feature of regulation in the United States, where a "Uniform System of Accounts" is used that classifies all utility accounts under a common system (International Energy Agency", 1994).

In order to overcome asymmetric information, regulators must also have adequate, although suitably restricted, discretional powers and considerable administrative and financial resources.

There are several information-extracting mechanisms by which a regulator can reduce the information advantage that the regulated industry enjoys.

One of these is the issue of licenses (franchising), or competition for the market. Where direct market competition is not possible within an industry, franchising, or competition for the right to be the monopolist, is another information-extracting mechanism. When many interested parties facing the same technology and production costs present non-collusive bids for the right to be the monopolist, the competition for the market among the ex-ante producers will hold in check the potential informational advantage of the ex-post supplier through the competitively determined terms of the franchise contract. This approach is being increasingly used in Latin America and the Caribbean, examples of it being the concessions and related arrangements in Argentina and Mexico. Despite their many interesting features, however, franchising arrangements suffer from serious limitations (ECLAC, 1997; Williamson, 1976), and the activities of the drinking water and sanitation sector are particularly subject to these difficulties. The most important obstacles include the danger that bidding for the franchise will cease to be competitive; problems connected with the visibility and transferability of investments, which may distort both the incentives to invest and the nature of the competition for franchises; and difficulties in specifying and administering the contracts.
The most promising attempt to formally address the problem of asymmetric information in privatized water supply and sanitation services seems to be through benchmark or yardstick competition, also known as competition by comparison or competition by example. This method promotes competition in cost minimization between monopolists indirectly, via the regulatory mechanism, by replicating comparisons with the performance of similar firms elsewhere. The basic principle behind this proposal is to decouple the utility company's price structure from its own reported costs and hence limit its opportunities to distort its cost data. The opportunities for the use of benchmark competition in the drinking water and sanitation services industry detive from the fact that - as a result of the common regulatory structure and many common features in the operational environment and the input and output markets of the service providers- when setting prices or target service quality levels for one firm, the performance statistics of other firms usually contain information signals concerning the underlying economic trade-offs faced by the given firm's management (Vickers and Yarrow, 1988). It is not easy to implement benchmark competition, however. Regulators have found it difficult to incorporate it explicitly in regulatory frameworks (Cowan, 1993; Helm, 1994), but in spite of the problems it raises it is being increasingly used in the regulation of both the price and the quality of the services provided.

The advantages of benchmark competition are part of the case for having horizontally separated companies rather than a single national company in natural monopoly industries (Vickers, 1995). Mergers, takeovers; joint management arrangements and other changes in the industry structure can affect the regulator's ability to make effective use of benchmark competition. This does not rule out mergers, but since the loss or degradation of comparators, particularty among bigger or more efficient companies, adversely affects the efficiency of benchmark competition, regulators should seek to create new and improved comparators and to link this with immediate benefits to customers, notably in the form of lower prices (OFWAT, 1995a). 


\section{IV}

\section{Conduct regulation}

Although as a general rule the most suitable policy for promoting efficiency is the adoption of structural reforms designed to encourage competition, the special features of drinking water and sanitation services, especially in relatively small countries or those with a low level of economic development, limit the possibilities of such restructuring. In situations like these, conduct regulation becomes the most important if not the only instrument.

Conduct regulation is concerned with different aspects of the behaviour of regulated firms, such as their pricing policy, the quality of the products and services they offer, investments, etc. The aim of this type of regulation is to reproduce, in a monopoly industry, the same kind of outcome as would be found in a competitive situation and to create the same incentives as competitors would have generated in a competitive market.

Conduct regulation has traditionally focussed on activities such as monitoring, control and auditing. It is very similar to the relation which exists between a State-owned monopoly and the ministry which oversees it. The more modern approach to conduct regulation emphasizes economic incentives that compel regulated companies to operate efficiently.

\section{Price regulation}

\section{a) Explicit price regulation}

Perhaps the most visible form of conduct regulation is price regulation. There are many price regulation mechanisms, but all fall somewhere along a continuum between the extremes of rate-of-return regulation (the traditional method of regulating public services in many countries, especially the United States) and price-cap regulation, which was applied in England and Wales in the mid-1980s.

In recent years, traditional rate-of-neturn regulation has been criticized for two main reasons: i) because it provides poor incentives to minimize costs and innovate, and ii) because it encourages firms to use an inefficiently high capital/abour ratio for their level of output: the so-called Averch-Johnson effect (see Averch and Johnson, 1962). A series of empiri- cal studies of the United States drinking water and sanitation industry have been unable to find significant differences between the relative efficiency of private utilities subject to rate-of-return regulation and public utilities, which would appear to confirm the low incentive properties of rate-of-retum regulation (see Feigenbaum and Teeples, 1983; Bymes, Grosskopf and Hayes, 1986; Lambert, Dichev and Raffiee, 1993).

Apart from the criticisms made regarding its limited capacity to provide incentives, however, rate-ofreturn regulation does have some advantages. By providing a solid guarantee of a fair rate of return, it offers a type of long-term commitment which is crucial for investments with a high sunk cost component, as in the drinking water and sanitation sector (Laffont, 1994). It also defines a feasible procedure which gives investors guarantees against the risk of bankruptcy and provides for a strong system of checks and balances. Furthermore, rate-of-retum regulation is likely to have a downwand impact on the cost of capital (Grout, 1995). Although it may provide weaker incentives for cost reduction, it generally performs well in the presence of cost uncertainty and asymmetric information about the capabilities of regulated firms, and it reduces the ability of the regulated firm to profit from regulatory ignorance or favourable cost shocks (Schmalensee, 1989).

Price-cap regulation attempts to avoid the problems associated with rate-of-return regulation (particularly its tendency to put upward pressure on costs), while at the same time limiting the scope for regulatory failure and reducing the burden of regulation. It is argued that regulation of prices rather than profits provides strong incentives to improve efficiency and make innovations in production technology and the supply of services, helps to promote competition, and also focusses regulation precisely on the particular services where market failure and public concem are greatest, so ensuring that consumers are effectively protected against monopoly abuse.

Perthaps the most serious drawbacks of this option have to do with the difficulty of establishing

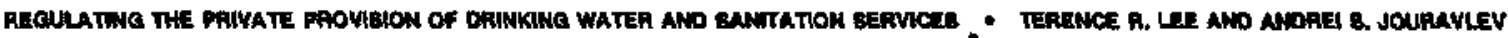


price adjustment factors and the uncertainty surrounding the process, which can translate into higher capital costs and discourage investment. Even more serious is the fact that under this system a regulated firm's profits may diverge considerably from normal or reasonable levels, which suggests that it might be difficult for govemments to opt for regulation based exclusively on price caps. Inevitably, in a monopolistic and highly capital-intensive industry like drinking water and sanitation services, the regulatory authorities quickly came to the conclusion that price controls must be complemented with an assessment of capital expenditure requirements, including recognition of the financial implications of capital expenditure for price adjustments (Jeffery, 1994). This blurs the difference between the price-cap approach and rate-of-return regulation.

Nevertheless, there are strong reasons for preferring price-cap regulation initially following privatization, mainly because productivity gains are potentially larger at the time of privatization than subsequently, so that the improved incentive properties of price-cap regulation are particularly important during that period (Beesley and Littlechild, 1989). In industries with a decentralized industrial structure, the reasons for preferring price-cap regulation initially are reinforced by the regulator's possibility of generating superior information and overcoming the asymmetry of information through benchmark or yardstick competition. Furthermore, since price-cap regulation can effectively control the prices charged by dominant firms when the competitive marketplace controls the profits, it has been suggested that this form of regulation is probably most effective and appropriate as a transitory step on the path towards total deregulation and full competition (Braeutigam and Panzar, 1993; Schmalensee, 1995).

Although, in their pure forms, these two mechanisms may appear very different, their characteristics in terms of incentives to reduce costs and invest efficiently are very similar in the real world, where either mechanism usually includes aspects of the other, with the result that their strong points and weaknesses tend to be very similar. For instance, regulatory lags and automatic price adjustments reinforce the incentives under rate-of-return regulation and cause it to more closely resemble price-cap regulation, while the need to guarantee private investors a reasonable rate of return on their capital brings price- cap regulation closer to rate-of-return regulation and introduces the same flaws. What matters is not what the system is called, but rather such factors as the length of the regulatory lag and the expectations that the system generates among investors as to how and on what basis prices are to be readjusted (Jones, 1994).

The tariff-setting process currently used in Chile for drinking water supply and sanitation services is a good example of a process incorporating aspects of several different approaches.

First, rates are determined on the basis of a simulation of a "model firm", which is defined as a firm whose aim is to provide drinking water and sanitation services efficiently, within the prevailing regulatory framework, taking into account the geographical, demographic and technological constraints under which the firm must operate. This represents a form of benchmark competition, since the costs considered in the pricing process are those which the model firm would incur rather than those of its real-world counterpart, and this, at least in theory, prevents the institutionalization of inefficiencies and encourages regulated firms to improve productivity. The drawback of this approach arises out of the basic problem of asymmetric information: if the regulatory agency uses the actual costs of the real-world firm, it validates any of the firm's possible inefficiencies and gives it an incentive to manipulate the information it provides to the regulator. Accordingly, the regulator will be obliged to use other sources of information which are not perfect either.

Second, maximum rates are fixed for a period of five years. In order to make this relatively long regulatory Jag feasible, rates are indexed in order to maintain their real value. These characteristics introduce some features of price-cap regulation into the set-up, since regulated firms stand to benefit from any cost-cutting they implement before the next periodic review.

Third, the system incorporates some elements of rate-of-return regulation, since the rates are calculated in such a way as to generate a return on assets of not less than 7\%. Moreover, if before the next periodic review it is shown that the basic assumptions used for pricing have changed significantly, then the rate-setting formulas may be modified by mutual consent of the regulator and the firm in question. 
b) Implicit regulation of prices or other aspects of conduct

Commercial code regulation, also known as "potential" or "implicit" regulation or "regulation by threat", does not require a sector-specific regulatory framework. Firms operate freely without specific regulation, but regulators monitor and evaluate their performance on the basis of principles established by competition or anti-trust legislation in general; furthermore, there is a credible threat of regulatory intervention if firms engage in anti-competitive behaviour, if prices rise too much or if quality becomes compromised or customers are not reasonably satisfied.

Studies of the behaviour of firms threatened with regulation (Glazer and McMillan, 1992) suggest that:

i) Their behaviour is determined by the marginal effect of changes in price on the probability of regulation;

ii) An unregulated monopoly will consider the effect of its pricing policy on the probability of regulation:

iii) Because under the threat of regulation a monopoly lowers its prices to prevent regulation, the actual imposition of regulation may have little effect on its prices or expected profits; and

iv) Firms may alter their prices more in response to changes in the perceived probability or strictness of regulation than its actual imposition.

Commercial code regulation is relatively simple to implement, it is very inexpensive, and it provides a means to institute regulation gradually: all factors which are particularly important in countries with litthe experience in formal regulation. It is particularly suitable where the cost of errors is low and as a temporary measure to protect consumers against monopoly power until competition arrives. On the other hand, the rational fear that some future govermment will impose strict price regulation will force the firm not to increase its profits excessively, which it can achieve by keeping prices low but also by not working too hard and not pursuing every opportunity to reduce costs (Jones, 1994).

\section{Service quality regulation}

a) Various means of regulating service quality

A reduction in product quality or service standards is equivalent to an increase in price. Without adequate regulation of the quality of service pro- vided, price regulation may be rendered ineffective: "buyers can be exploited just as effectively by giving them poor or unsafe service as by charging them excessive prices" (Kahn, 1988).

At the present time, competition in the basic transport and distribution services of drinking water and sanitation utilities, as well as the possibility of shifting demand, are very limited or non-existent in most cases. In addition, markets for water-related services are typically characterized by informational asymmetries between suppliers and consumers, and the suppliers of the services usually operate as monopolies. For these reasons, it is very unlikely that price control alone can give firms which are seeking to maximize their profits incentives to adopt socially optimal quality options (Shapiro, 1983; Leland, 1979; Spence, 1975). There is therefore a strong case for supplementing price regulation with the regulation of service quality.

The most common methods of quality regulation include the following (Rovizzi and Thompson, 1995):

i) The publication and dissemination of information on service quality is a simple and inexpensive way to put public pressure on any company providing substandard service and may also encourage new competitors to enter the market, but it provides few incentives to improve quality.

ii) Civil liability-based schemes and the like have significant advantages: they can give private firms strong incentives to improve quality, their supervision and enforcement are decentralized, they are flexible because they allow firms to make up for changes in the quality of service by increasing their costs, and customers receive compensation for poor service. They can result in high transaction costs, however, and they are more appropriate when quality failures can be easily verified. They would seem particularly appropriate for supply interruptions, ration. ing and similar problems. Because they are costly and difficult to implement, civil liability schemes are more suited to bulk consumers.

iii) Customer compensation schemes or guaranteed standards of performance, in contrast, are usually more appropriate for the majority of normal customers, especially when the quality faults are easily observable. They involve the setting of standards of service backed by a system of financial penalties payable in the event of non-compliance either to the government or, preferably, directly to the affected 
customers. In England and Wales, for example, the Guaranteed Standards Scheme provides for fixed payments to be made when the company fails to meet certain guaranteed service standards (OFWAT, 1995b). This scheme currently provides for a flat-rate payment of $£ 10$ (about US\$15) in respect of each failure to meet the guaranteed standard, except for sewer flooding, where the payment is a refund of the customer's annual sanitation charge. Payments for some service failures are made automatically: if they are not made within ten working days of the failure, the customer is entitled to an additional payment. For other failures, claims must be made in writing by the customer.

iv) In order to be more effective, minimum quality of service standards should be backed by explicit legal sanctions, such as fines or license amendment or revocation, or by an implicit threat to revise the regulated price or to impose enforceable quality of service standards, and in order to be more efficient, standards should be set with reference to the benefits of regulation and its costs. They are appropriate for situations where there are informational asymmetries between suppliers and customers and where small changes in quality can give rise to serious damage (Rovizzi and Thompson, 1995).

v) Finally, there is the possibility of incorporating a measure of service quality explicitly in the price-control formula or taking it into account implicitly at the regulatory review. This mechanism may include action to reduce prices, profits or revenues when a firm fails to meet quality standards or the initiation of a regulatory review in the event of service quality falling below some preset levels. A well-implemented mechanism of this kind would mimic the incentives existing in competitive markets, but it involves a heavy informational burden. In any case, the pricing process should take into account the quality-related aspects of the regulated products and services, and the regulator should therefore monitor the regulated firm to ensure that it meets the quality standards specified in its tariffs.

\section{b) The common agency problem}

When a firm faces several different regulators for quality of service, pollution and other environmental aspects, and prices, whose preferences in respect of the various possible actions often conflict with each other, what is generally referred to as the common agency problem can arise. This can lead to tensions between the regulators and create the danger of inefficient outcomes (Baron, 1985 and 1989).

This potential for inefficiency underlines the need for closer cooperation between the regulatory agencies, for institutional procedures that guarantee collective decision-making, for the responsibilities of regulatory agencies to be compatible, and for an explicit duty to be imposed on the environmental regulator to balance costs against benefits, as long as legal obligations are not compromised (Cowan, 1993). In the privatized water industry in England and Wales, the Office of Water Services (OFWAT), as economic regulator, does not decide on environmental policies but it ensures that decision-makers have all the necessary facts, strives to ensure that costing data are available and that sufficient solutions have been considered, and is concemed that companies should be able to plan their investment programmes in a reasonably stable regulatory environment (Booker, 1994). It impresses on the qualityregulating agencies the importance of carrying out adequate economic analysis before they adopt more stringent standards.

\section{Regulation of quantity}

Many water-related goods and services form a small but indispensable part of the total cost of the wide range of products in which they are used and meet needs that consumers cannot readily forego. As a consequence, the losses from service failure can be very large in financial, social and political terms, relative to the basic cost of provision of the service. For this reason, public service utilities are usually subject to universal service obligations, that is to say, obligations to serve all those who live within their area, apply for service, and are willing and able to pay for it. Without such an obligation, utilities will not have a motivation to provide service when the costs of satisfying demand temporarily increase. For public utility industries, this requirement sometimes means that they must make capital investments in unprofitable areas or must maintain an unprofitable type of service, but more commonly it means that utilities must expand capacity ahead of demand growth (Phillips, 1993).

The universal service obligation means that in the case of an essential public service the public sector can never wholly abdicate its responsibilities for the operation of that service, as it can in some other 
industries, without placing the public at risk. Given that the operator of last resort will always be the public sector, governments should probably consider either regulating privatized water-related utitities more comprehensively or foregoing more comprehensive regulation but charging the privatized firm a risk premium for "public insurance" to cover the contingent costs of public sector intervention should the firm enter into a critical operating condition (Devlin, 1993). An alternative, albeit less attractive, would be for the public sector to retain the residual means of providing essential services should the private sector fail to perform its functions.

\section{Regulating investment}

Many of the benefits of private sector participation in the drinking water supply and sanitation industry result from the fact that such participation protects necessary but politically dispensable investments from unfavourable budgetary pressures. It also provides a means of tapping the greater pool of private capital to help finance them. The direct object of regulation is usually pricing policy, but the effect of regulation on social welfare depends critically on the investment behaviour that price regulation induces in regulated firms (Vickers and Yarrow, 1988). Given the nature and technological characteristics of the water supply and sanitation sector, the advantages of private participation are likely to be small unless there is private participation in investment.

An adequate supply of private finance will only be forthcoming if investors are confident that their investment will not disappear through direct expropriation or through a series of small regulatory actions that are tantamount to a de facto expropriation, and that they will obtain a rate of return on the capital invested which is commensurate with the risk they take. The problem of regulatory commitment "arises from a fundamental asymmetry: the regulated price is flexible but the regulated firm's capital stock is not" (Besanko and Spulber, 1992). Since the economic life of many of the components of drinking water supply and sanitation infrastructure is extremely long and moreover these structures cannot be relocated to other areas or given altemative uses, the profitability of investment depends not so much on the initial regulatory framework as it does on the decisions sub. sequently taken by the regulator after the investment or privatization has been carried out.

Potential investors need government commitment to respect in the long term their property rights, the rules and regulations governing tariffs, entry conditions, and expansion plans. It is essential, therefore, to develop a stable regulatory environment to encourage and maintain private investment in water-related services. Unless there is such a stable environment, the rational fear of $e x$ post opportunism by governments will deter efficient investment in sunk cost assets. The only secure route to private sector confidence is a history of rational government committed to policies encouraging private investment in public services. These considerations underline the impor. tance of ensuring transparent and stable regulatory standards which will uphold the State's commitment to recognize the need for a long-term level of profitability acceptable to the private investor. In addition, the regulatory framework should be flexible enough to adapt to changes in markets, as well as in the economic, institutional, social and technological spheres.

One effect of privatization will be to significantly increase the discount rate applied to investment projects, as the discount factors used by governments are usually low. This means that privatization can affect the choice of technology. If a government decides to use subsidies to encourage the private sector to follow a specific investment path, attention should be paid to the need to ensure that any subsidies are channeled to the most efficient companies and do not affect the play of the market" forces too much.

When prices are regulated, regulatory agencies must carefully monitor the capital and maintenance spending of the regulated firms to ensure that they make the investments allowed for in the price limits on time and achieve the expansion, quality and other targets for which the investments bad been proposed. The need for close monitoring is underlined by the capital-intensive nature of most drinking water supply and sanitation utilities, which provides scope for evading the constraints imposed by price regulation, by reorganizing their investment profile to enhance short-term financial performance at the possible expense of longer-term efficiency and prospects (Bishop and Kay, 1989). 


\section{$\mathbf{V}$}

\section{Structure regulation}

There may be different reasons for implementing structural reforms, the most important being:

i) In the case of potentially competitive industries, to encourage competition, not for competition's sake but as a means of achieving cost effectiveness or eliminating or reducing the need for conduct regulation; and

ii) In the case of industries such as drinking water and sanitation, where competition is not possible for technological reasons, to improve access to information and facilitate conduct regulation.

When considering structural reforms, it is important to bear in mind that they are by no means a panacea. Attempts to separate closely interdependent activities can impose high costs on the sector, including the loss of economies of scale and scope, the cost of the system coordination machinery, the costs of restructuring the sector, and the possible loss of some internalization of externalities. Such costs need to be carefully weighed against the potential benefits of cost-minimizing behaviour in a situation of competitive pressure. If these factors are significant, there might be justification for continuing with an integrated monopoly.

\section{Horlzontal restructuring}

Horizontal restructuring means integrating or separating identical production processes on a territorial basis or by service categories. A typical example of horizontal separation is the subdivision of national drinking water supply and sanitation companies into regional or municipal units.

In some cases -for example, when the size of the market far exceeds the optimum scale of production and transport costs ane insignificant compared with those of production- horizontal separation can create dinect competition. This model has been applied in various countries in the electricity sector, but it is not directly applicable to the drinking water supply and sanitation sector, because there are generally no national or regional networks. In some cases, however, it is possible to create competition between regional enterprises for big industrial or commercial clients or for the right to supply clients located on the edges of the companies' service areas.

Perhaps the main advantage of horizontal separation, even when it leads to local monopolies (unless there is no correlation in the cost conditions among them) is that it enables regulators to have access to information from a group of independent providers of comparable services. This provides a basis for comparisons between firms which are useful for setting incentives based on relative performance and hence creating opportunities for the application of more effective regulatory incentive structures based on comparable yardsticks or benchmarks. In addition, the existence of several companies opens up the industry to competition between them in the capital market.

Horizontal separation can also mean, however, that regulators are faced with the prospect of regulating and monitoring a considerable number of firms, which may cause serious administrative problems.

\section{Vertical restructuring}

Vertical restructuring concerns the integration or separation of the different processes needed to make the final product or service available to the consumer. A typical example of vertical separation is the division of a State-owned electric power utility into separate generating, transmission and distribution companies.

Although vertical integration in competitive markets often increases efficiency and social wellbeing, the vertical integration of monopoly firms can be a source of concern for regulators for various reasons:

i) Vertical integration can allow a natural monopoly to extend its monopoly power to nonregulated upstream and downstream markets by discriminating in its own favour or in favour of affiliated firms, increasing barriers to entry, and foreclosing competitors by such means as prohibitive network access charges or discrimination in other aspects of interconnection, and 
ii) Vertical integration usually worsens the asymmetry of information between regulators and firms and impairs the quality of the information available to the regulator, thus hindering effective conduct regulation and providing opportunities for circumvention.

These considerations suggest that the regulator should try to identify the component or components of water resource infrastructure which establish a utility as a natural monopoly and attempt as far as possible to isolate those activities that may be described as an intrinsic natural monopoly from other activities or production processes that cannot be described as such. This separation seeks to prevent companies that integrate various production segments from using one of these to obtain undue advantages from others or from concealing inefficiencies by transfening profits eamed elsewhere to them.

So far, vertical reforms of this type have been applied more extensively in the electricity sector, but they are not directly applicable to the drinking water supply and sanitation sector, where the scope for increasing competition through vertical structural reforms is extremely limited if not non-existent, because of the strength of the natural monopoly conditions deriving from the established local networks of water mains and sewers. The obstacles are the need for extremely tight coordination between the services, due to the interrelated demand, the high costs of service delivery in relation to the costs of water production or wastewater treatment, and the fact that the experience gained and the equipment used in one activity is useful in the other.

\section{Diversification of regulated firme}

The diversification of any firm has many advantages, since it makes it possible to spread risks, compensate for fluctuations in demand, make better use of the firm's capacity, and secure other benefits which can be reflected in lower costs and better service.

In spite of its potential benefits, however, the diversficication of regulated firms can be a source of concern for regulators for several reasons (Armstrong, Cowan and Vickers, 1994):

i) Difficulties in the unregulated activity could negatively affect the regulated firm's ability to raise capital and operate its core business;

ii) Diversification of a firm makes estimation of the cost of capital more difficult, and if the firm diversifies into a riskier business this might raise that cost;

iii) The operation of the non-core business might consume excessive amounts of the time and resources of the regulated firm's management.

Diversification of a regulated firm can also worsen the asymmetry of information between the regulator and the firm and reduce the regulator's ability to implement benchmark competition, by reducing the number of available comparators. It also allows scope for cross-subsidization through transfer pricing in intra-company transactions.

For these reasons, the authorities should be alert to the impact of the diversification of regulated firms, althongh it would not be appropriate to prohibit diversification entirely, since it can give economies of scale and scope and open up the possibility of reducing costs. An important question is how to structure the regulatory system to take advantage of the positive aspects of diversification while avoiding its undesirable effects. The main point is to ensure transparency of transactions between regulated and unregulated activities, to avoid cross-subsidies, and to guarantee access by the regulator to the information he needs to fulfill his objectives. 


\section{VI}

\section{Regulating public utilities in}

\section{Latin America and the Carlbbean:}

\section{the present situation}

Almost all the Latin American and Caribbean governments have adopted policies to increase private sector participation in the provision of drinking water supply and sanitation services. The actual nature of these policies varies greatly from one country to another. Only a few of them have opted to completely transfer the administration of these services to the private sector, generally in the form of concessions, as in Argentina and Bolivia. Elsewhere, as in Chile and Venezuela, decentralization and regulation within the public sector has been the policy adopted, with private sector participation limited to contractual service arrangements of a more technical nature.

As regards regulatory policy, however, the Latin American and Caribbean countries have two clear priorities: the development of effective regulatory capacity and the establishment of the independence of regulatory authorities, which should be free of direct political interference. At the same time, it is necessary for those defining regulatory policy to be absolutely clear as to what the real objectives of such policy must be.

It is not easy to develop a regulatory system, and it has been necessary to formulate systems which can rapidly incorporate the lessons of experience, since it is impossible to predict all problems from the start. The main obstacles are lack of experience and a relatively steep learning curve. It is for this reason that the functions of the regulator must be clearly defined and strictly limited to the absolutely necessary. In general, this is why price regulation is the preferred basic approach, leaving other decisions to the managers of the utilities. Regulation of service quality has its own intrinsic importance, however.

Adequate information is of paramount importance for effective regulation. The most promising path for the countries of the region to formally address the problem of asymmetric information seems to be some form of benchmark competition. The advantages of benchmark competition are part of the case for having a horizontally separated rather than national structure in water supply and sanitation services.

The effect of regulation on social welfare depends critically on the investment behaviour that it induces in regulated firms. In general, there is no shortage of capital in the world for investment in this sector; on the contrary, it is perfectly possible to set a flow of investment in motion, as shown by the example of the electric power sector. For this to take place, however, potential investors need government commitment not only to respect their property rights over the long run but also to create a stable regulatory environment that will encourage and maintain private investment in water-related services. As already noted, the only secure route to private sector confidence is a history of rational government committed to policies that encourage private investment in public services.

(Original: English) 


\section{Bibliography}

Acton, J. P. and I. Vogelsang (1989): Introduction, The Rand Journal of Economics, vol. 20, No. 3, Lawrence, KS.

Armstrong, M., S. Cowan and J. Vickers (1994): Regulatory reform: Economic analysis and British experience, MIT Press Series on the Regulation of Economic Activity, No. 20, Cambridge, MA, The MTT Press.

Averch, H. and L. Johnson (1962): Behavior of the firm under regulatory constraint, The American Economic Review, vol. 52, No. 5, Nashville, TN, American Economic Association.

Baron, D. (1985): Noncooperative regulation of a nonlocalized extemality, The Rand Journal of Economics, vol. 16, No. 4, Lawrence, KS.

(1989): Design of regulatory mechanisms and institutions, in R. Schmalensee and R. D. Willig (eds.), Handbook of Industrial Organization, vol, 2, Handbooks in economics, book 10, Amsterdam, Netherlands, Elsevier Science Publishers.

Beesley, M. E. and S.C. Littlechild (1989): The regulation of privatized monopolies in the United Kingdom, The Rand Journal of Economics, vol. 20, No. 3 Lawrence, KS.

Besanko, D. and D. Spulber (1992): Sequential-equilibrium investment by regulated firms, The Rand Joumal of Economics, vol. 23, No. 2, Lawrence, KS.

Bishop, M. and J. Kay (1989): Privatization in the United Kingdom: Lessons from experience, World Development, vol. 17. No. 5, Oxford, U. K., Pergamon Press plc.

Booker, A. (1994): British privatization: Balancing needs, American Water Works Association Joumal, Denver, CO, AWWA, March.

Braeutigam, R. and J. Panzar (1993): Effects of the change from rate-of-return to price-cap regulation, The American Economic Review. Papers and Proceedings of the Hundred and Fifth Annual Meeting of the American Economic Association, vol. 83, No. 2, Nashville, TN, American Economic Association.

Byrnes, P., S. Grosskopf and K. Hayes (1986): Efficiency and ownership: Further evidence, The Review of Economics and Statistics, vol. 68, No. 2, Amsterdam, Elsevier Science Publishers BV.

Cowan, S. (1993): Regulation of several market failures; The water industry in England and Wales, Oxford Review of Economic Policy, vol. 9, No. 4, London, Oxford University Press.

Devlin, R. (1993): Privatizations and social welfare, CEPAL Review, No. 49, LC/G.1757-P, Santiago, Chile, ECLAC.
ECLAC (Economic Commission for Latin America and the Caribbean) (1997): Private Participation in the Provision of Water Services. Alternative Means for Private Participation in the Provision of Water Services, vol. 1, LC/R.1576, Santiago, Chile.

Feigenbaum, S, and R. Teeples (1983): Public versus private water delivery: $A$ hedonic cost approach, The Review of Economics and Statistics, vol. 65, No. 4, Amsterdam, Harvard University.

Glezer, A. and H. McMillan (1992): Pricing by the firm under regulatory threat, The Quarterly Journal of Economics, vol. 107, No. 3, Cambridge, MA, The MIT Press.

Grout, P. (1995): The cost of capital in regulated industries, in M. Bishop, J. Kay and C. Mayer (eds.), The Regulatory Challenge, Oxford, U. K., Oxford University Press.

Helm, D. (1994): Price limits do not hold water, The Tines, London, Times Newspapers, 29 July.

International Energy Agency (1994): The Electricity Supply Industry: Structure, Ownership and Regulation in OECD Counstries, Paris, Organization for Economic Cooperation and Development (OECD).

Jeffery, J. (1994): Privatization in England and Wales, American Water Works Association Joumal, vol. 80, No. 13, Denver, CO, AWWA, March.

Jones, L. (1994): Appropriate regulatory technology: The interplay of economic and institutional conditions, Proceedings of the World Bank Annual Conference on Development Economics. 1993, Washington, D.C., World Bank.

Kabn, A. (1988): The Economics of Regulation: Principles and Institutions, Cambridge, MA, The MTT Press.

Laffont, J. (1994): The new economics of regulation ten years after, Econometrica, vol. 62, No. 3, Evanston, IL, The Econometric Society.

Lambert, D., D. Dichev and K. Raffiee (1993): Ownership and sources of inefficiency in the provision of water services, Water Resources Research, vol. 29, No. 6, Washington, D. C., American Geophysical Union.

Leland, H. (1979): Quacks, lemons, and licensing: A theory of minimum quality standards, Journal of Political Economy, vol. 87, No. 6, Chicago, IL, The University of Chicago.

OFWAT (Office of Water Services) (1995a): Looking forward from the periodic review: OfWAT publishes 1994 annual report, Press Notice, No. 14, Birmingham, OFWAT, 21 June.

(1995b): OFWAT publishes consultation paper on compensation following 1995 drought, Press Notice, No, 40, Birmingham, OFWAT, 20 December. 
Perry, M. (1984): Scale economies, imperfect competition and public policy, The Journal of Industrial Economics, vol. 32, No. 3, Oxford, U. K., Basil Blackwell

Phillips, C. (1993): The Regulation of Public Utilities: Theory and Practice, Arlington, VA, Public Utilities Reports, Inc.

Rovizzi, $L$. and D. Thompson (1995): The regulation of product quality in the public utilities, in M. Bishop, J. Kay and C. Mayer (eds.), The Regulatory Challenge, Oxford, U. K, Oxford University Press.

Sappington, D. (1994): Designing incentive regulation, Review of Industrial Organization, vol. 9, No. 3, The Netherlands, Kluwer Academic Publishers.

Schmalensee, R. (1989): Good regulatory regimes, The Rand Joumal of Economics, vol. 20, No. 3, Lawrence, $\mathbf{K S}$.

(1995): What have we leamed about privatization and regulatory reform?, Revista de Análisis Económico, vol. 10, No. 2, Santiago, Chile, Instituto Latinoamericano de Doctrina y Estudios Sociales (LADES).
Shapiro, C. (1983): Premiums for high quality products as returns to reputations, The Quarterly Joumal of Economics, vol. 98, No. 4, John Wiley \& Sons.

Spence, M. (1975): Monopoly, quality, and regulation, The Bell Journal of Economics, vol, 6, No. 2, New York, American Telephone and Telegraph Company.

Vickers, J. (1991): Government regulatory policy, Oxford Review of Economic Policy, vol. 7, No. 3, London, Oxford University Press.

- (1995): Concepts of competition, Oxford Economic Papers, vol, 47, No. 1, London, Oxford University Press.

Vickers, J. and G. Yarrow (1988): Privatization: An economic analysis, MIT Press Series on the Regulation of Economic Activity, No. 18, Cambridge, MA, The MIT Press.

Williamson, O. (1976): Franchise bidding for natural monopolies - in general and with respect to CATV, The Bell Joumal of Ecanomics, vol. 7, No. 1, New York, American Telephone and Telegraph Company. 